\title{
Value of serial $P$ wave changes in indicating left heart failure in myocardial infarction
}

\author{
Juhani Heikkilä and Kimmo Luomanmäki \\ From the Cardiovascular Laboratory, First Department of Medicine, \\ University Central Hospital, Haartmaninkatu 4, Helsinki 29, Finland
}

In order to evaluate ventricular failure in acute myocardial infarction, electrocardiographic left atrial overloading was correlated to several simultaneous clinical and radiological signs of left ventricular dysfunction in 200 consecutive patients. Analyses were made at three time periods after infarction. Left atrial overloading, measured by $P$ terminal force, was significantly associated with the signs of left ventricular dysfunction, though in this unselected series of infarctions the prevalence of abnormal values was not high (46\%). This finding is to be considered rather as a contributory sign than as a diagnostic one in the entire clinical picture. In an individual patient, however, conspicuous serial changes are helpful in indicating the direction of course of the haemodynamic disorder. The prognostic value of the $P$ terminal force was found to be significant.

The electrocardiographic concept of ' $P$ mitrale' is widely used for recognition of left atrial involvement in heart diseases. It is characterized by a prolonged, notched $P$ wave, and a shift to left and posteriorly of the terminal forces of the $\mathbf{P}$ wave. In mitral valvar disease these $\mathbf{P}$ wave changes are usually associated with anatomical atrial enlargement (Reynolds, 1953; Saunders et al., 1967). In addition, the haemodynamic load on the left ventricle is shared by its filling reservoir, the left atrium, and impairment of left ventricular performance should, therefore, be indicated by $\mathbf{P}$ wave changes. Electrocardiographic $a b-$ normalities constituting evidence of such haemodynamic burden on the left atrium have been reported in aortic stenosis (Gooch et al., 1966), hypertension (Tarazi et al., I966), exercise (Cortes, I963), and left ventricular failure (Wood and Selzer, 1939; Sutnick and Soloff, I962).

Recently, Grossman and Delman (1969) described serial $P$ wave changes in 24 selected patients with acute myocardial infarction. Systematic studies of the $P$ wave alterations and of their prevalence in acute myocardial infarction are few (Master, 1933; Miori and Mazzei, I965; Sitar, 1965; Heikkilä, 1967; Semin, Trushinsky, and Murashko, 1968). The fact that left heart pump failure complicates most cases of acute cardiac infarctions (Julian and Oliver, 1968) instigated the present survey of

Received 25 November 1969. serial changes and prevalence of abnormal $\mathbf{P}$ waves in 210 consecutive patients with acute myocardial infarction. The sensitivity of the $\mathbf{P}$ waves in indicating haemodynamic overload of the acutely damaged left ventricle, and the prognostic significance of the atrial electrocardiogram were assessed.

\section{Subjects and methods}

Patients The present analysis is based on the data of a prospective clinical investigation on acute myocardial infarction. The criteria and description of the clinical methods used have been presented before (Heikkilä, I967). The 2 Io consecutive patients with acute infarction were observed carefully daily during the first ro days, and thereafter every other day until they were discharged.

The clinical features which were recorded and estimated for their severity included: clinical left ventricular failure (score $0-2$ ), palpable paradoxical cardiac pulsation (score o-2), pulmonary oedema, ventricular and atrial gallop sounds, splitting of the second heart sound and accentuation of its pulmonary component, and cardiac murmurs. Particular attention was paid to acute papillary muscle dysfunction; the mitral regurgitant murmurs (phonocardiographically established) were divided into two groups for coarse quantitation. In the first group, the early and late ejectiontype, proto-mesosystolic and decrescendo-type pansystolic murmurs were considered to indicate slight regurgitation (Nager, Kaufmann, and Schaub, 1964; Heikkilä, 1967). In the other group, different types of pansystolic murmur (plateau, crescendo, spindle) tend to occur together with more conspicuous mitral incompetence (Fig. I). 
Chest x-rays $X$-rays were available from the subacute phase 3 to 4 weeks after infarction and from the 6 months' follow-up. The heart volume was measured, the size of the left atrium was estimated from plain $x$-rays, and scored $0-3$, and the radiological signs of left ventricular failure were scored o-4: 0 - normal, I - pulmonary venous dilatation, 2 - interstitial oedema, 3 - venoconstriction in the lower fields and septal lines, 4 - frank alveolar oedema (Fig. 2).

Electrocardiograms (a) Equipment and procedure A direct-writing ink-jet apparatus (Mingograph, Elema-Schönander) with linear response up to 500 c.p.s. was mainly used. A gain was employed which produced $10 \mathrm{~mm}$. deflection for I $\mathrm{mV}$ calibration potential. The paper speed was $50 \mathrm{~mm}$./sec., which enables the small $P$ wave alterations to be detected with reasonable accuracy. An average value from several electrocardiographic complexes was used in order to avoid the effect of respiratory changes in the position of the heart. Electrocardiograms of three time periods were analysed in detail; the first was recorded on one of the initial 5 days, the second 3 to 4 weeks after onset of infarction, and the third tracing was from the follow-up study after 6 months on the average. The initial tracing was recorded with a few exceptions only before, and the second after, development of acute mitral incompetence in cases where this complication occurred.

(b) Assessment of the myocardial infarction The location of the recent infarction was assessed as anterior or postero-inferior and its extent as transmural or subtransmural.

(c) Selection of electrocardiographic criteria for recognition of left atrial overloading There is strong evidence suggesting that the $\mathbf{P}$ terminal force in the horizontal plane is one of the most rapid and sensitive parameters for predicting left atrial overloading, even in the absence of ana-

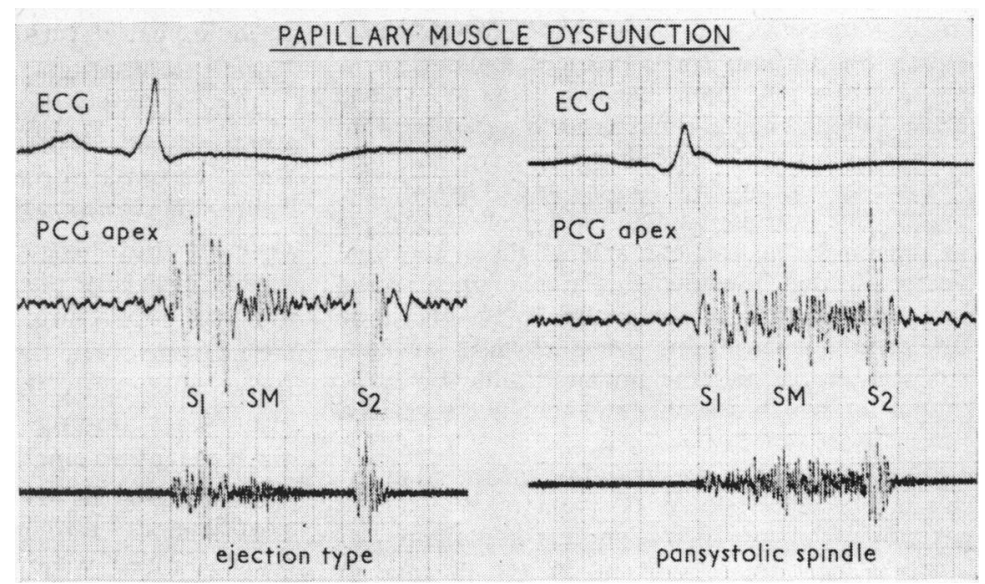

FIG. I Phonocardiograms in papillary muscle dysfunction. Ejection-type mitral systolic murmur $(S M)$ is associated with slight mitral regurgitation, while the pansystolic murmur with mid-systolic crescendo denotes conspicuous volume overload.

tomical atrial enlargement but under increased pressure from the haemodynamic burden (Sutnick and Soloff, 1962; Morris et al., 1964; Gooch et al., 1966; Saunders et al., 1967; Heikkilä,1967; Siltanen, 1968; Kasser and Kennedy, 1969). This parameter was therefore deemed to be most suitable for the following analysis. The $P$ terminal force was determined from the duration and amplitude of the terminal deflection of the $P$ wave in lead VI. Negative values in excess of -0.030

FIG. 2 X-rays showing slight (grade I) and severe (grade 4) pulmonary vascular congestion. Left, lower field venous dilatation; right, lower field vasoconstriction, upper field venous dilatation, septal lines, alveolar oedema.
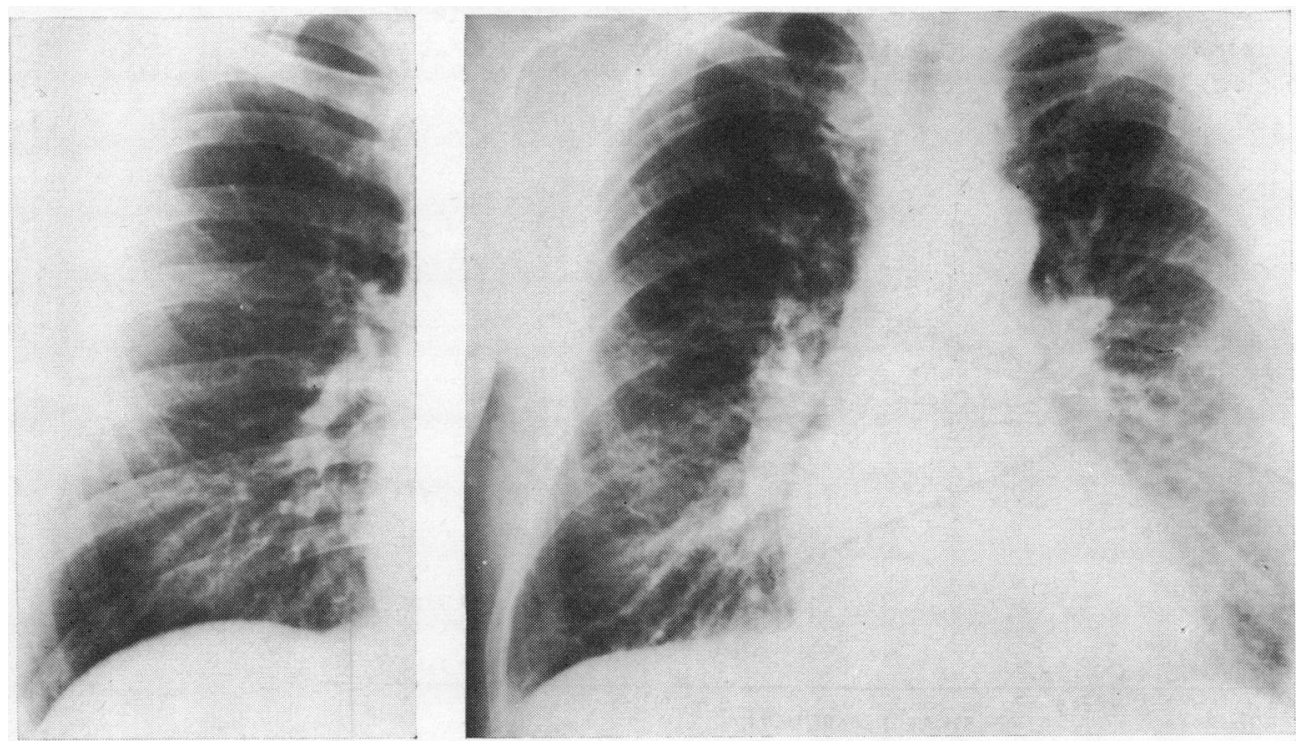
msec. were considered pathological (Morris et al., 1964). Significance tests were also performed in relation to a still more negative value of -0.040 msec., which is sometimes used as a demarcation between normal and pathological $P$ terminal forces (Tarazi et al., 1966; Burch and DePasquale, 1967). The duration and amplitude of the $P$ wave in bipolar leads, and the axis of the $P$ terminal vector in the frontal plane in the uncorrected hexaxial system were also analysed. These criteria disclosed no significant serial changes or conspicuous deviation from normal limits (Heikkilä, r967), for which reason they were not subjected to any more detailed analysis.

The $\mathbf{P}$ terminal forces could be measured at the initial phase in 200 of the total series of 210 patients with acute infarction, in 196 patients 3 to 4 weeks after infarction, and in 150 patients at follow-up. Tracings with atrial fibrillation (5 patients during the stay in hospital), atrial ectopic rhythm, or signs suggesting atrial infarction were not included.

The dynamics of the $\mathbf{P}$ terminal force in the phases of cardiac infarction were studied; the presence and degree of clinical features observed in the course of acute myocardial infarction were related to the simultaneously determined values of the $\mathbf{P}$ terminal force. The prognostic value of alteration in the $\mathbf{P}$ terminal force was tested, using the findings in 30 patients with sinus rhythm who died in hospital, mainly from pump failure.

The recorded data were punched on cards and processed in an IBM I620 computer.

\section{Results}

Relation of $P$ terminal force and its serial changes to clinical features Altogether 92 patients out of $200(46 \%)$ had

FIG. 3 Correlation of electrocardiographic left atrial overloading with clinical and radiological signs of left ventricular dysfunction at three time periods after acute myocardial infarction. Significant intercorrelations are also shown $\left({ }^{\star \star \star} p<0.001,{ }^{\star} \star_{p}<0.01,{ }^{\star} p<0.1\right)$. pathological $\mathrm{P}$ terminal force in one of the three examinations.

Fig. 3 shows those correlations that were found to be statistically significant between the $\mathbf{P}$ terminal force and the occurrence and degree of various clinical variables, including radiological evidence of left ventricular failure, in the three time periods, studied by computer analysis. The clinical variables which yielded significant correlation with the $\mathbf{P}$ terminal force, when only the presence or absence of abnormal findings was considered and analysed by means of fourfold point correlation coefficients, are illustrated in Fig. 4. The significances remained similar even when -0.040 msec. was used instead of -0.030 for the upper limit of normal, except that at the subacute phase the third heart sound was then associated with a $\mathbf{P}$ terminal force at a higher significant level $(p<0.01)$, and at follow-up its relation with myocardial asynergy became probably significant $(p<0.05)$.

\section{During the initial days of infarction}

Of the 200 patients, 23 per cent had a pathologically negative value, exceeding -0.030 msec. Statistically significant correlation was present only between the $P$ terminal force and myocardial asynergy, as manifested by unequivocally palpable paradoxical cardiac pulsation. In the fourfold point correlations, considering only normal and abnormal findings without quantitative grading, clinical left heart failure also became significantly associated with pathological $P$ terminal force. The third heart sound accompanied myocardial asynergy and clinical heart failure, but its presence was not directly related to the $\mathbf{P}$ terminal forces during these first days of infarction.

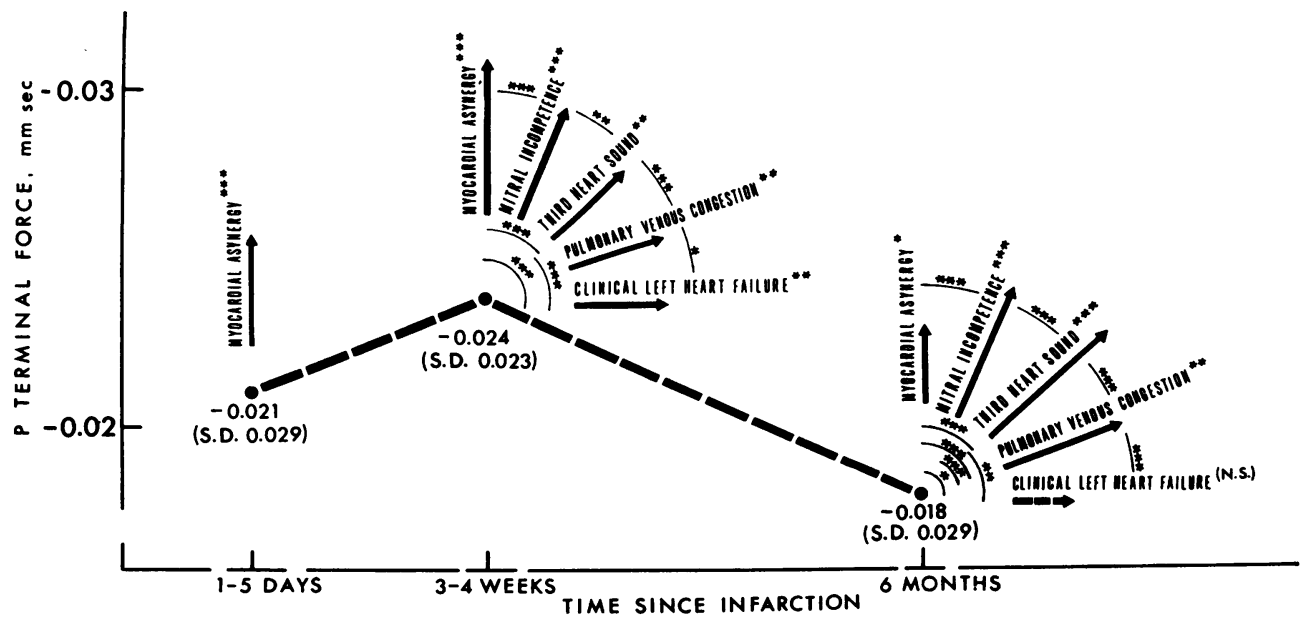




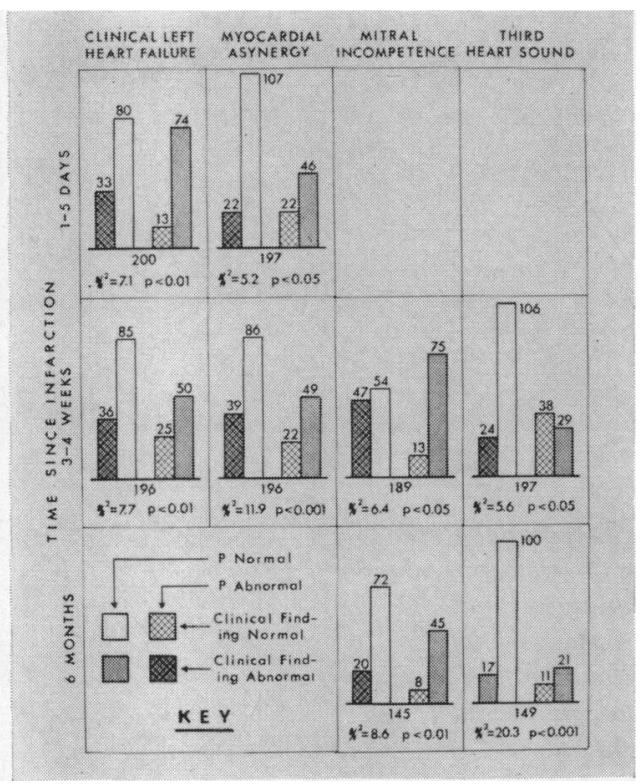

FIG. 4 Number of $P$ terminal forces presenting concordant or discordant association with simultaneously observed clinical findings. Data without significant correlation to P terminal force are not shown.

During period of 3-4 weeks after onset of infarction

The mean $\mathbf{P}$ terminal force had shifted towards more pathological values, while still remaining within normal limits. The number of pathological values had increased to $3 \mathrm{r}$ per cent of the patients. At this stage, several clinical factors presented a significant association with the $\mathbf{P}$ terminal force. Of these, myocardial asynergy and acute papillary muscle dysfunction correlated most strongly with the $P$ terminal force in the analysis involving the semiquantitative approach. The manifold interrelations also present between the different clinical factors are shown in Fig. 3. All these factors, however, reflect a decrease in left ventricular pumping capacity. Though the number of pathological P terminal forces at this time did not differ greatly from that in the initial phase, changes of $P$ terminal force in the course of time were still common in individual patients. Conspicuous changes occurred sometimes very rapidly within a few days. For example, initially abnormal $\mathbf{P}$ terminal forces returned to normal after clearing of pulmonary oedema or after less severe transient heart failure on admission; on the other hand, the initially normal or abnormal P terminal force often became progressively more pathological, especially with the development of acute mitral regurgitation (Table, Fig. 5-9).
TABLE Changes of $P$ terminal force in relation to acute papillary muscle dysfunction.

\begin{tabular}{llll}
\hline $\begin{array}{llll}\text { Change of } \\
\text { P terminal force }\end{array}$ & \multicolumn{2}{l}{ Acute papillary muscle dysfunction } & \multirow{2}{*}{ Total } \\
\cline { 2 - 3 } & Present & Absent & \\
\hline Initially normal $\rightarrow$ abnormal & $24(73 \%)$ & $7(41 \%)$ & 31 \\
Initially abnormal $\rightarrow$ normal & $9(27 \%)$ & 10 $(59 \%)$ & 19 \\
\hline Total & 33 & 17 & 50
\end{tabular}

At 6 months' follow-up

The electrocardiographic left atrial overloading was least. Only 19 per cent of the 150 patients had an abnormal value of $P$ terminal force. Many patients with conspicuous left heart failure had died in the meantime. Mitral incompetence and the third heart sound were always significantly associated with left atrial overloading, while less significant correlation was noted in respect of the other variables studied.

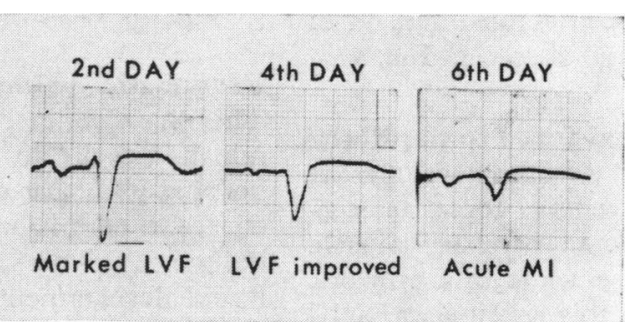

FIG. 5 Alterations of $P$ terminal force $\left(V_{1}\right)$ revealing the rapidly changing haemodynamic state in acute myocardial infarction. Clinical improvement of initial left ventricular failure (LVF) was accompanied by relief of electrocardiographic left atrial overloading for several days, but these signs recurred when the infarction progressed, with superimposition of acute mitral incompetence (MI).

FIG. 6 Serial conspicuous changes in P terminal force $\left(V_{1}\right)$, suggesting progressive impairment of left ventricular performance due to myocardial infarction and ischaemic papillary muscle dysfunction.

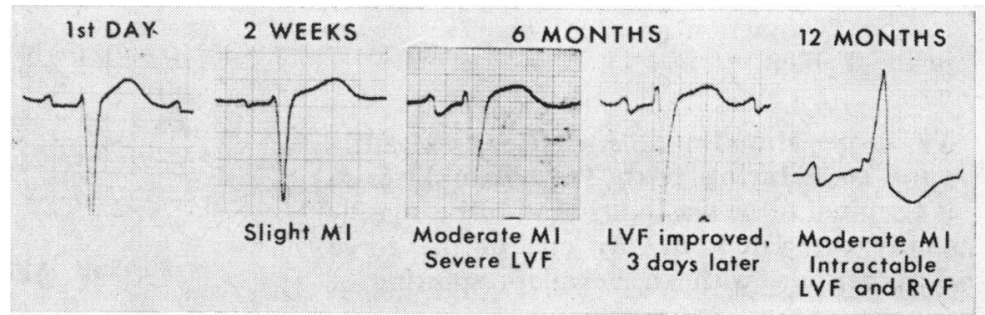




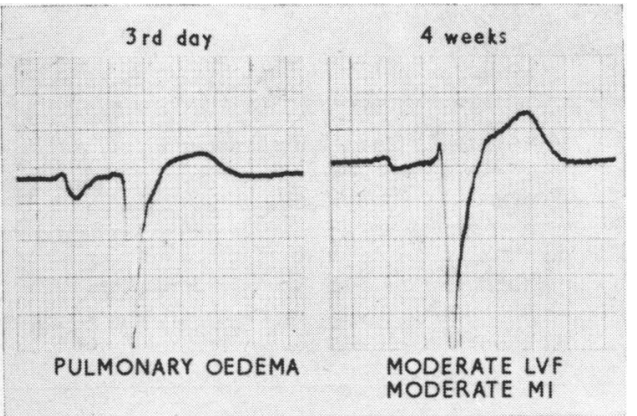

FIG. 7 Conspicuous concomitant decrease of electrocardiographic left atrial overloading $\left(V_{1}\right)$, with disappearance of initial pulmonary oedema due to acute myocardial infarction.

Relation of $\mathbf{P}$ terminal force to radiological findings $P$ terminal force correlated highly significantly with heart volume at both phases in which this was studied. The relative size of the left atrium became significantly correlated with $P$ terminal force only at the follow-up phase $(p<0.001)$. Pulmonary vascular congestion has been commented on in the preceding section and is seen in Fig. 3.

Relation of $\mathbf{P}$ terminal force to papillary muscle dysfunction Because development of the pathological P terminal force was significantly related to acute papillary muscle dysfunction in the present and in a previous study (Heikkilä, 1967), this relation was subjected to further analysis. (I) Changes in the degree of mitral incompetence were correlated with simultaneous differences in $\mathbf{P}$ terminal force from one examination to the next. This correlation was highly significant when the acute phase was compared with the subacute phase, but the correlation remained insignificant when the subacute was compared with the follow-up phases. The result of this longitudinal analysis between the three phases of study was negative with all the other clinical variables in relation to $\mathbf{P}$ terminal force. (2) An initially normal $P$ terminal force with subsequent abnormal development, or an initially pathological value which returned to normal by the subacute phase, was observed in 50 patients. The influence of acute papillary muscle dysfunction on such changes appears in the Table.

Variables showing no statistically significant correlation with $P$ terminal force P terminal force was not found to be significantly correlated, in any one of the three time periods, with atrial gallop, splitting of

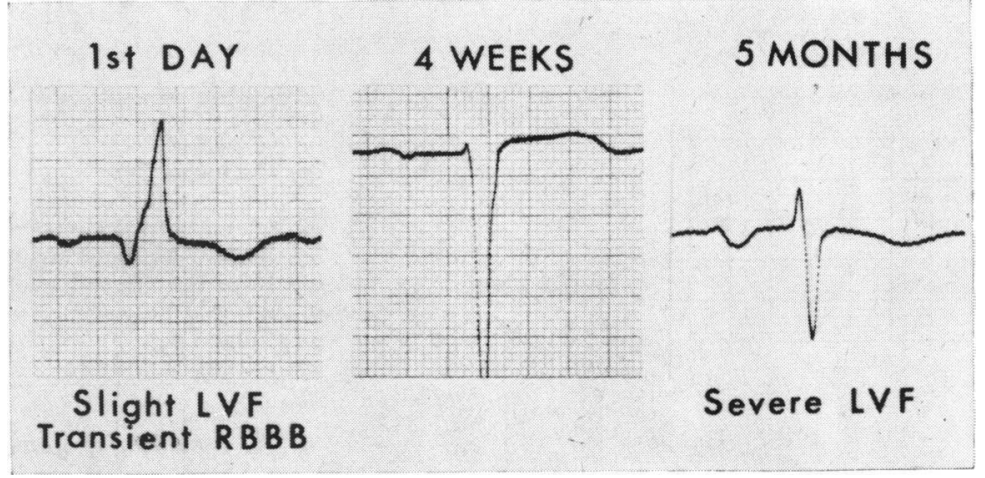

FIG. 8 Increase of the $P$ terminal force $\left(V_{1}\right)$ with delayed appearance of left ventricular failure after cardiac infarction. Loud ventricular gallop and conspicuous left ventricular failure were found at follow-up examination, from clinical, radiological, and cardiac catheterization studies.

the second heart sound or accentuation of its pulmonary component, and extent and location of the recent myocardial infarction.

\section{Prognostic value of $P$ terminal force} This was examined by comparing the $P$ terminal force in 30 patients who died in the hospital with that of 166 patients discharged alive. On admission, there was no significant difference $\left(\chi^{2}=3 \cdot 8\right)$ between the two groups. Rapid development of $\mathbf{P}$ terminal force in a more pathological direction was associated highly significantly with mortality. At the subacute phase (in patients dying earlier, a tracing taken before the death was used), a negative value of $\mathbf{P}$ terminal force exceeding $-0.040 \mathrm{msec}$. was found in $4 \mathrm{I}$ per cent $(23 \%$ on admission) of the patients with fatal termination of their acute infarction, and in only 8 per cent ( $12 \%$ on admission) of the survivors $\left(\chi^{2}=27 \cdot 1, p<0.001\right)$. The importance of acute mitral incompetence in producing this electrocardiographic change, associated with an un-

FIG. 9 Electrocardiograms $\left(V_{1}\right)$ showing occasional insensitivity of $P$ terminal force in recognition of established left heart failure.

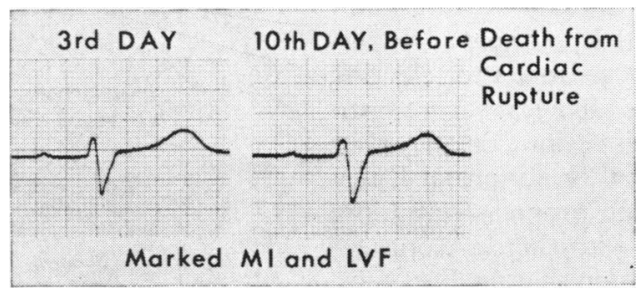


favourable prognosis, was reported earlier (Heikkilä, I967).

\section{Discussion}

Left ventricular failure in myocardial infarction Pump failure is almost the rule in acute transmural myocardial infarction (Fluck et al., I967; Heikkilä, I967; Sampson and Hutchinson, 1967; Julian and Oliver, 1968; Tattersfield et al., 1969). Recent experience from coronary care units has shown the importance of early diagnosis of left ventricular failure in acute infarction. This deterioration of mechanical efficiency seems to be mainly governed by myocardial asynergy, which apparently is always present (Tennant and Wiggers, I935; Suh and Eddleman, 1959; Heikkilä, Luomanmäki, and Pyörälä, 1970), in that the ischaemic or destroyed portion of the ventricular wall entirely fails to contract or contracts abnormally (Herman et al., 1967). Acute ischaemic papillary muscle dysfunction adds varying amounts of regurgitant volume load on the damaged ventricle in about half of the patients with acute infarction. The frequent interference in the function of the papillary muscles in acute cardiac infarction is probably related to infarction of the papillary muscles themselves, in association with an impaired contraction pattern of their damaged supporting ventricular wall (Heikkilä, 1967, 1969). Consequently, the left atrial pressure tends to be raised both owing to the increased end-diastolic pressure of the failing ventricle and as a result of mitral incompetence. However, clinical findings have not always revealed pump failure observed at serial $x$-ray or haemodynamic investigations (Roughgarden, 1966; Fluck et al., 1967; Julian and Oliver, 1968; Tattersfield et al., 1969).

Value of electrocardiographic left atrial overloading in indicating pump failure Significant correlation was found in our study between the electrocardiographic left atrial overloading and the degree and serial changes of various clinical and radiological signs of left ventricular dysfunction in acute myocardial infarction. This correlation increased in the course of time. In the initial phase, the pathological $P$ terminal force was accompanied by palpable myocardial asynergy, while at a later time acquisition of acute papillary muscle dysfunction and ventricular gallop became the main single factors affecting the $P$ terminal force. The effect of arterial blood pressure on the acute changes of $P$ terminal force was found to be insignificant in an earlier analysis (Heikkilä, 1967). The prog- nostic value of the dynamic alteration in $P$ terminal force was significant, and agrees with the findings of Sitar (1965).

In spite of these significant correlations, the $r$ values were low, $0.20-0.50$, and the number of $P$ waves reaching pathological values $(46 \%)$ remained, in this series of consecutive patients, less than reported by others in acute myocardial infarction (Master, 1933; Schmidt and Hilmer, I95I; Miori and Mazzei, 1965; Sitar, 1965; Abrate, 1967; Semin et al., 1968). However, in several of these studies on $P$ waves only a qualitative estimation was reported. Subtransmural infarction with little ventricular failure might also explain this finding in a large series of unselected infarctions. However, clinical findings of left ventricular failure still prevailed in about twothirds of the patients, and there was no significant difference in $\mathbf{P}$ terminal force in relation to the extent of infarction. The considerable serial changes occurring in opposite directions (discussed later) also tend to reduce the number of pathological $\mathbf{P}$ terminal forces at each time of observation, depending on the stage of evolution in the pump failure.

$P$ terminal force is one of the most sensitive electrocardiographic criteria for detection of left atrial overloading, notable even in the case of pure pressure increases, with little anatomical enlargement (Morris et al., 1964; Saunders et al., 1967; Kasser and Kennedy, 1969). However, its correlation coefficient with left atrial involvement is not very high, and about a quarter of all atrial enlargements may not be associated with pathological $P$ waves. Thus, because of this methodical factor, and on the basis of the results of the present clinical study, the suggestions of the value of left atrial electrocardiographic abnormality as a sensitive indicator of heart failure (Wood and Selzer, I939; Schmidt and Hilmer, I95I; Sutnick and Soloff, 1962) should not be applied too strictly. Single measurements of $\mathbf{P}$ terminal force alone do not seem to rank high among several commonly found clinical signs indicating ventricular failure. A contributory value only should be assigned to this measurement when considered in association with other findings.

However, the serial $P$ wave abnormalities are frequently conspicuous in individual patients, and may occur swiftly within a few days; this was sometimes helpful in predicting the subsequent course of clinical heart failure. The most rapid and the greatest changes in $P$ terminal force occurred in the following two groups of patients. Initial pulmonary oedema of acute infarction was associated with abnormal $\mathbf{P}$ terminal forces, with frequent return 
to normal within a few days when the acute haemodynamic strain was cleared. This pattern of transient initial abnormalities was reported in other types of $\mathbf{P}$ wave changes in acute infarction by Grossman and Delman (1969), Sitar (1965), and Abrate (1967). Conversely, severe acute papillary muscle dysfunction is a serious complication capable of leading to serious deterioration in the performance of the damaged left ventricle (Heikkilä, 1967, 1969). Rapid changes in electrocardiographic left atrial overloading sensitively indicated this haemodynamic disorder of more delayed onset, both in the total series of patients and in those who died in hospital (Heikkilä, 1967).

Mechanism of acute serial $P$ wave changes The fairly close relation between acute papillary muscle dysfunction and the serial changes in the $P$ waves seems to indicate the importance of regurgitant surge, in addition to the raised diastolic pressure of the failing left ventricle itself, in distending the left atrium (Hawley, Dodge, and Graham, 1966). Atrial distension might provide a pathophysiological mechanism for the often conspicuous rotation of the $P$ terminal vector posteriorly in the horizontal plane. Posterior rotation of the atrial activation vector has previously been recorded in congestive heart failure (Sutnick and Soloff, 1962), while changes in the frontal plane did not occur systematically in acute myocardial infarction (Heikkilä, 1967). Anatomical enlargement of the left atrium does not occur rapidly, even under severe acute mitral regurgitation (Raftery, Oakley, and Goodwin, 1966), but the electrocardiogram may indicate a haemodynamic burden imposed upon the left atrium. The haemodynamic load seems to be a more relevant mechanism for the frequent serial $P$ wave changes in acute myocardial infarction, as judged from their reversibility and significant association with signs of left ventricular pump failure, than are atrial ischaemia or infarction (Freundlich and Sereno, 1959; Liu, Greenspan, and Piccirillo, 196I) or other progressive muscle degeneration (Hundt and Schleimer, 1959). Sympathetic drive and hypoxia, capable of causing acute $P$ wave alterations, are nevertheless manifestations of ventricular failure when they occur in acute infarction (Penneys and Thomas, 1950; Valori, Thomas, and Shillingford, 1967).

Interestingly, there was no correlation between atrial gallop sound and electrocardiographic left atrial overloading, nor, more significantly, with any of the clinical and radiological signs of ventricular failure which were studied. This finding contrasts with observations in hypertension where a close correlation has been reported (Tarazi, Frohlich, and Dustan, 1969). Some mechanism other than established congestive heart failure or hypertrophic restrictive myopathy (Goldblatt, Aygen, and Braunwald, 1962; Meerschwan, 1969) seems, then, to be involved in atrial gallop in acute myocardial infarction, where it is present almost invariably (Hill et al., 1969; Heikkilä et al., 1970).

\section{References}

Abrate, M. (1967). Alterazioni dell atriogramma nell infarto del miocardio. Minerva Cardioangiologica, I5, 451 .

Burch, G. E., and DePasquale, N. P. (1967). Electrocardiography in the Diagnosis of Congenital Heart Disease. Lea and Febiger, Philadelphia.

Cortes, F. M. (1963). Acute atrial overloading, a response to stress. American fournal of the Medical Sciences, 246, 443.

Fluck, D. C., Valentine, P. A., Treister, B., Higgs, B., Reid, D. N., Steiner, R. E., and Mounsey, J. P. D. (1967). Right heart pressures in acute myocardial infarction. British Heart fournal, 29, 748.

Freundlich, J., and Sereno, L. R. (1959). Auricular infarction. American Heart fournal, 57, 654 .

Goldblatt, A., Aygen, M. M., and Braunwald, E. (1962). Hemodynamic-phonocardiographic correlations of the fourth heart sound in aortic stenosis. Circulation, 26, 92.

Gooch, A. S., Calatayud, J. B., Rogers, J. B., and Gorman, P. A. (I966). Analysis of the $P$ wave in severe aortic stenosis. Diseases of the Chest, 49, 459.

Grossman, J. I., and Delman, A. J. (1969). Serial P wave changes in acute myocardial infarction. American Heart Fournal, 77, 336.

Hawley, R. R., Dodge, H. T., and Graham, T. P. (1966). Left atrial volume and its changes in heart disease. Circulation, 34, 989.

Heikkilä, J. (1967). Mitral incompetence as a complication of acute myocardial infarction. (Thesis, Helsinki.) Acta Medica Scandinavica, 182, Suppl. 475. (1969). Acute mitral incompetence in myocardial infarction. Clinical recognition. Geriatrics, 24, 150. , Luomanmäki, K., and Pyörälä, K. (1970). Left ventricular dysfunction in acute myocardial infarction (Abstract). Scandinavian fournal of Clinical and Laboratory Investigation, 25, Suppl. I $13,40$.

Herman, M. V., Heinle, R. A., Klein, M. D., and Gorlin, R. (1967). Localized disorders in myocardial contraction. Asynergy and its role in congestive heart failure. New England fournal of Medicine, 277, 222.

Hill, J. C., O'Rourke, R. A., Lewis, R. P., and McGranahan, G. M. (1969). The diagnostic value of the atrial gallop in acute myocardial infarction. American Heart fournal, 78, 194.

Hundt, H.-J., and Schleimer, J.-H. (1959). Zur Häufigkeit der Verbreiterung der Vorhofzacke im Elektrokardiogramm und mögliche Beziehungen zur Koronarsklerose. Zeitschrift für Kreislaufforschung, 48, 1120.

Julian, D. G., and Oliver, M. F. (1968). Acute Myocardial Infarction. E. \& S. Livingstone, Edinburgh and London.

Kasser, I., and Kennedy, J. W. (1969). The relationship of increased left atrial volume and pressure to abnormal $\mathbf{P}$ waves on the electrocardiogram. Circulation, 39, 339. 
Liu, C. K., Greenspan, G., and Piccirillo, R. T. (196r) Atrial infarction of the heart. Circulation, 23, 33I.

Master, A. M. (I933). P-wave changes in acute coronary artery occlusion. American Heart fournal, 8, 462.

Meerschwan, I. S. (1969). Hypertrophic Obstructive Cardiomyopathy. Excerpta Medica Foundation, Amsterdam.

Miori, R., and Mazzei, G. (1965). Il quadro elettrocardiografico di ingrandimento atriale sinistro in corso di infarto miocardico e il suo significato. Minerva Cardioangiologica, 13, 65.

Morris, J. J., Jr., Estes, E. H., Jr., Whalen, R. E., Thompson, H. K., Jr., and McIntosh, H. D. (I964). $\mathbf{P}$-wave analysis in valvular heart disease. Circulation, 29, 242.

Nager, F., Kaufmann, G., and Schaub, F. (1964). Die Leistungsfähigkeit mechanokardiographischer Untersuchungen in der Erfassung der Mitralinsuffzienz und ihres Schweregrades unter besonderer Berücksichtigung der kombinierten Mitralvitien. Cardiologia, 44, 218.

Penneys, R., and Thomas, C. B. (1950). The relationship between the arterial oxygen saturation and the cardiovascular response to induced anoxemia in normal young adults. Circulation, 1, 415.

Raftery, E. B., Oakley, C. M., and Goodwin, J. F. (I966). Acute subvalvar mitral incompetence. Lancet, 2, 360.

Reynolds, G. (1953). The atrial electrogram in mitral stenosis. British Heart fournal, 15, 250.

Roughgarden, J. W. (1966). Circulatory changes associated with spontaneous angina pectoris. American fournal of Medicine, 4I, 947.

Sampson, J. J., and Hutchinson, J. C. (1967). Heart failure in myocardial infarction. Progress in Cardiovascular Disease, 10, $\mathbf{x}$.

Saunders, J. L., Calatayud, J. B., Schulz, K. J., Maranhao, V., Gooch, A. S., and Goldberg, H. (1967). Evaluation of ECG criteria for P-wave abnormalities. American Heart fournal, 74, 757.
Schmidt, J., and Hilmer, W. (195I). Untersuchungen über die P-Zacke des Elektrokardiogramms. I. Das P-sinistro-cardiale. Zeitschrift für Kreislaufforschung, 40, 275.

Semin, N. D., Trushinsky, Z. K., and Murashko, V. V. (1968). Alteration of the $P$ wave in myocardial infarction. Klinischeskaya Meditsina, 46, No. 6, p. 85.

Siltanen, P. (1968). Atrial septal defect of secundum type in adults. (Thesis, Helsinki.) Acta Medica Scandinavica, 185, Suppl. 497.

Sitar, J. (1965). The clinical significance of the Psinistrocardiale in left ventricular myocardial infarction. Cor et Vasa, 7, 30r.

Suh, Soon Kyu, and Eddleman, E. E., Jr. (1959). Kinetocardiographic findings of myocardial infarction. Circulation, 19, 531.

Sutnick, A. I., and Soloff, L. A. (1962). Posterior rotation of the atrial vector. An electrocardiographic sign of left ventricular failure. Circulation, 26, 913.

Tarazi, R. C., Frohlich, E. D., and Dustan, H. P. (1969). Left atrial abnormality and ventricular preejection period in hypertension. Diseases of the Chest, 55, 214.

—, Miller, A., Frohlich, E. D., and Dustan, H. P. (I966). Electrocardiographic changes reflecting left atrial abnormality in hypertension. Circulation, 34, 818.

Tattersfield, A. E., McNicol, M. W., Shawdon, H., and Rolfe, D. (1969). Chest X-ray film in acute myocardial infarction. British Medical fournal, 3, 332.

Tennant, R., and Wiggers, C. J. (1935). Effect of coronary occlusion on myocardial contraction. American fournal of Physiology, 113, 129.

Valori, C., Thomas, M., and Shillingford, J. P. (1967). Urinary excretion of free noradrenaline and adrenaline following acute myocardial infarction. Lancet, I, 127 .

Wood, P., and Selzer, A. (1939). A new sign of left ventricular failure. British Heart fournal, $\mathbf{1}, 8 \mathrm{I}$ 